\title{
Mubil: Creating an Immersive Experience of Old Books to Support Learning in a Museum-Archive Environment
}

\author{
Alexandra Angeletaki ${ }^{1}$, Marcello Carrozzino $^{2}$, and Michail N. Giannakos ${ }^{3}$ \\ 1 Norwegian University of Science and Technology (NTNU) University Library, \\ Gunnerus branch, Trondheim, Norway \\ alexandra.angeletaki@ub.ntnu.no \\ 2 PERCRO, TECIP Institute, Scuola Superiore Sant'Anna, Pisa, Italy \\ m. carrozzino@sssup.it \\ ${ }^{3}$ Norwegian University of Science and Technology (NTNU), Trondheim, Norway \\ michail.giannakos@idi.ntnu.no
}

\begin{abstract}
In this paper we present our design approach of transposing old books and manuscripts using 3D technology in a game frame. MUBIL is an interdisciplinary collaboration initiated by the NTNU University library of Trondheim and PERCRO at Scuola Santa Anna in Pisa. The books are enriched with 3D objects, additional explanatory content, in pictures, drawings, videos audios and texts in both Norwegian and English. This experimental setting is also supplemented by a game, the Alchemist's lab with content related directly to the book of medicine by Adam Lonicer written in 1590. The experiment to be carried out in the digital lab is a reconstruction of a distillation process described in this particular book that can be played as an interactive game using a stereo Powerwall and Nvidia 3D glasses in our MUBIL digital Laboratory in Trondheim. The applications are under development and we present here the system description and the workshop design adapted to visits of school children in our 3D lab.
\end{abstract}

Keywords: Augmented Books, Cultural Heritage, Immersive Systems, 3D, Archives and Libraries, XVR Systems.

\section{Introduction}

Browsing pages of books, fragile to be handled, manipulating manuscripts or gaining a tactile experience of books as digital objects has long been surveyed [10]. Research on augmented books with 3D-representations has seen progress the last 10 years [4]. New types of interfaces, interaction techniques and tracking devices are developing at a rapid pace and become integrated into multi-modal interactive VR and AR interfaces [7]. MUBIL aims to explore the evaluation methodology around user interfaces in such immersive environments. Our focus is mainly on the user learning experience in such combined or hybrid environments where 3D technological representations of books and gaming applications blend 
together [2]. We believe as it is already pointed out by several studies that gaming activities provide structure for collaboration and promote knowledge seeking skills in many learning contexts [8]. Students are often motivated to interact and to be engaged throughout the learning process in a way that is meaningful for them[3].In our case study social conduct seems to both create engagement and meaning. Learning by playing in groups seems to stimulate collaboration and enriches the user experience of the book content transposed in virtual applications [6] as the ones presented here.

\section{System Description}

The technological tool we use to promote archive content in this study is $3 \mathrm{D}$ technology. Manuscripts are presented in the form of an interactive 3D book (augmented book). Users can freely explore the original pages of the book or access their translations into several languages.
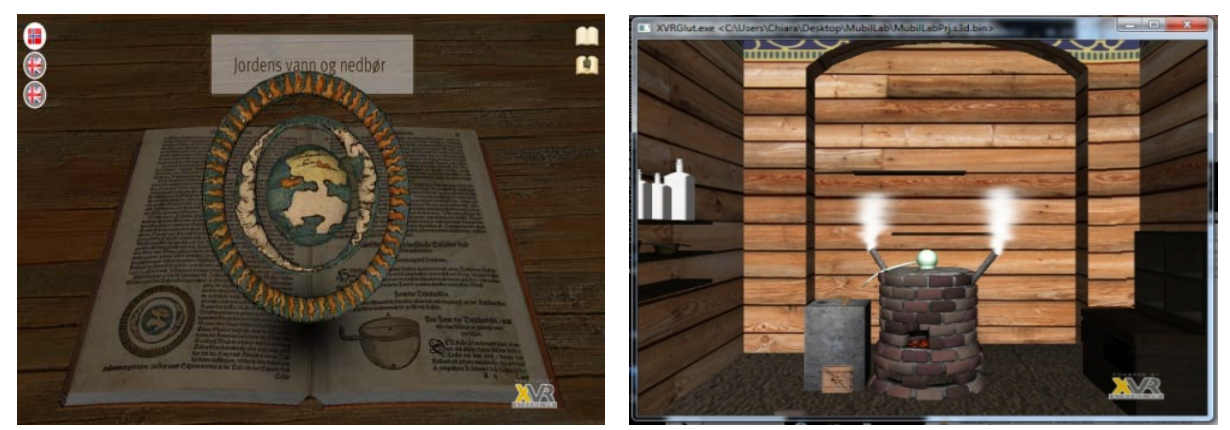

Fig. 1. Augmented book (left) and Virtual Lab (right)

An enhanced interaction modality enables the exploration of additional content purposely developed for the project such as 3D texts, images, movies, audios, real-time animated 3D models. In Figure 1 left, a page from the 3D transposition of Lonicer's treatise on medical distillation is presented. A second interaction level is represented by a virtual laboratory (Figure 1, right), where the user exploits knowledge from the previous level into an interactive lab application. The reader becomes an apprentice alchemist that must perform a real experiment based on the distillation notions acquired from the Lonicer treatise. A pointand-click interaction metaphor enables players to discover information, combine objects and perform all the operations involved in the distillation of a medicine. Thanks to the flexibility of the architecture (Fig. 2) and of the XVR underlying technology, both applications have been realized as blank container applications which can load a set of resources (XML schemas describing the application flow, textures, 3D models, videos, audios, music) in order to implement different books (in the case of augmented books) or to different experiments (in the case of the 


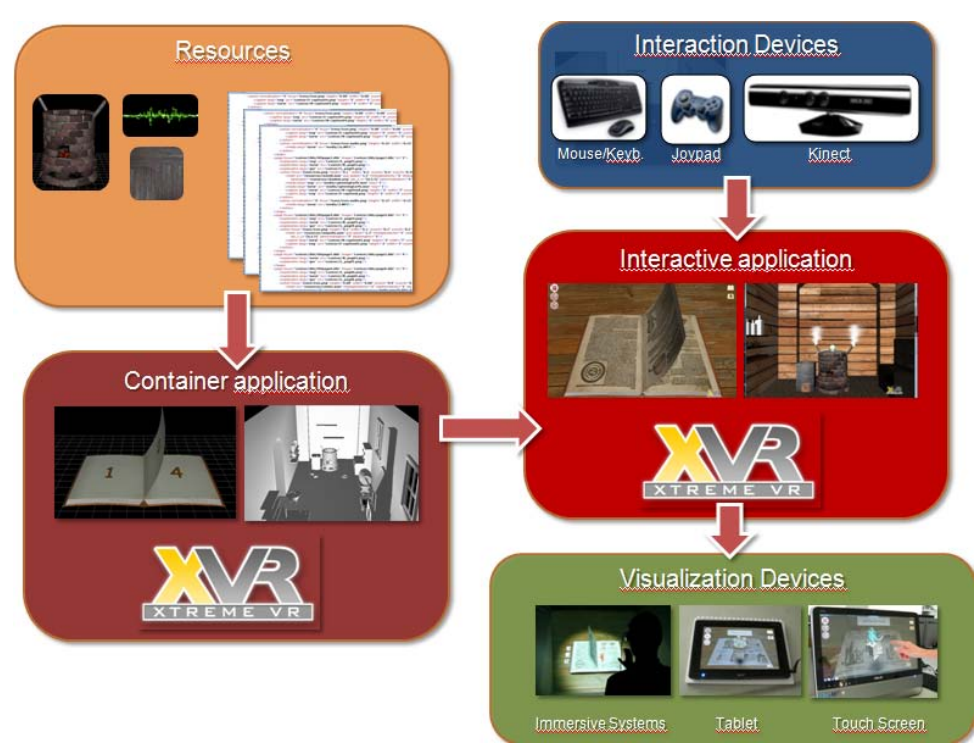

Fig. 2. Mubil high-level architecture

virtual lab). Several interaction metaphors have been implemented based on different devices (mouse, joystick, Microsoft Kinect etc.); all of these devices can be used to move a virtual pointer on the scene and execute actions of different types.

The same applies to visualization metaphors; this means that the $3 \mathrm{D}$ environment can be visualized on a simple flat screen, on a stereo screen or on a system of screens, therefore adapting to tablets, notebooks, and even immersive visualization systems such as CAVE. The software used for this prototype has already been used in several other applications [1].

\section{Workshop Design}

The first MUBIL prototype was evaluated by 40 High School students, invited to a day-workshop at our library-lab, last November 2012. They interacted with the applications in an environment of a simple Powerwall where the students used 3D Nvidia glasses and a simple mouse to browse through the book. The visit was organized as a field trip embedded in their curriculum and as a study activity on the history of chemistry. Two groups browsed first through the augmented book and the game prototype with no specific instruction or background information.

Two other groups were introduced, first to the content of the book and to the actual experiment described in the book of Adam Lonicer. A focusgroup of 6 students, the "experts" was interviewed after the interaction and will 


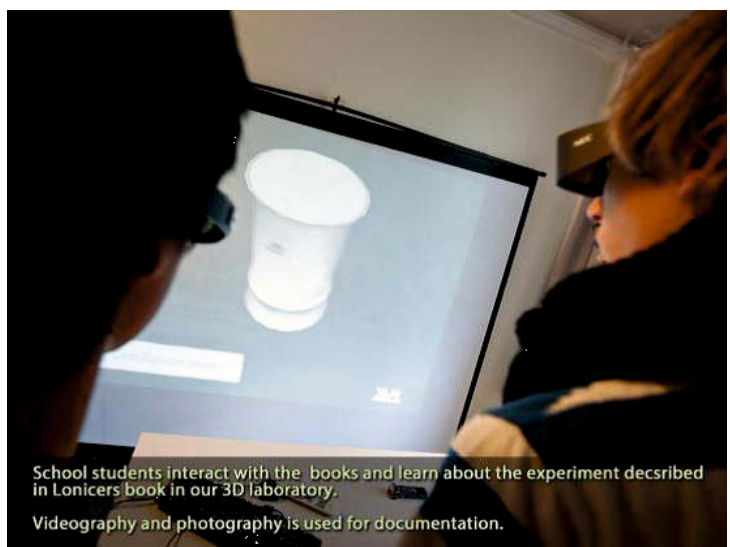

Fig. 3. School students interact with the books

evaluate the development of the applications in successive visits. They interacted through social conduct with both applications in the lab. All of the above was documented by 12 hours video recordings. All answered also pre- and post-tests and knowledge tests prepared by their chemistry teacher.

\section{Conclusions}

At present, we are still working with the development of the final applications and the design of the workshop visits. A usage interface evaluation is also under development based on guidelines proposed by other scholars [5]. A visit in such an environment or exhibition is defined here as a "cultural learning experience that occurs through observation, instruction, trial and error" [2]. The 3D book is tailored for our library as a digital version substitute protecting the original book from being handled. In the next step of this ongoing research after the completion and the launching of the applications at the end of 2013, we will invite more schools to participate in the Mubil work-shops, collect data on their performance and collaboration pattern, while in the XVR environment and try to analyze our results with a combined qualitative and quantitative methodology. We hope then to be able to define and compare different factors that affect their learning process.

Acknowledgements. We would like to thank the National library of Norway for the financial support of our project and Professor Letizia Jaccheri from NTNU, IDI for her support and supervision. We would like also to thank all our collaborators for their dedication to our work. 


\section{References}

1. Carrozzino, M., Brogi, A., Tecchia, F., Bergamasco, M.: The 3D interactive visit to Piazza dei Miracoli, Italy. In: Advances in Computer Entertainment technology, pp. 192-195 (2005)

2. Champion, E.: Playing with the Past, London, vol. 178 (2011)

3. Costabile, M.F., Ardito, C., Lanzilotti, R.: Enjoying cultural heritage thanks to mobile technology. Interactions 17(3) (2010)

4. Shiaw, H.-Y., Jacob, R.J.K., Crane, G.R.: The 3D vase museum: A new approach to context in a digital library. In: Proceedings of the 2004 Joint ACM/IEEE Conference on Paper Presented at the Digital Libraries (2004)

5. Bowman, D.A., Kruiiff, E., La Viola, J.J., Poupyrev, I.: 3D User Interfaces Theory and practice. Addison Wesley (2004)

6. Liarokapis, F., Sylaiou, S., Basu, A., Mourkoussis, N., White, M., Lister, P.F.: An interactive visualisation interface for virtual museums. In: Proc. of the VAST 2004, pp. 47-56 (2004)

7. Mikalef, K., Giannakos, M.N., Chorianopoulos, K., Jaccheri, L.: "Do not touch the paintings!" the benefits of interactivity on learning and future visits in a museum. In: Herrlich, M., Malaka, R., Masuch, M. (eds.) ICEC 2012. LNCS, vol. 7522, pp. 553-561. Springer, Heidelberg (2012)

8. Riva, G.: Towards cyberpsychology: mind, cognition and society in the internet age. IOS Press (2005)

9. Rogers, Y.: Introduction to distributed cognition. In: Brown, K. (ed.) The Encyclopedia of Language and Linguistics, pp. 181-202 (2006)

10. Almeida, R., Cubaud, P., Dupire, J., Natkin, S., Topol, A.: Experiments towards 3D immersive interaction for digital libraries. In: Pan, Z., Aylett, R.S., Diener, H., Jin, X., Göbel, S., Li, L. (eds.) Edutainment 2006. LNCS, vol. 3942, pp. 1348-1357. Springer, Heidelberg (2006) 